the microscopic punctures in the rubber caps and to coat them with a protecting envelope of paratin. For this purpose we again employ the solution of rubber which is sold for the purpose of repairing bicycle tyres. Before applying it, the remains of the antiseptic solution are first cleaned off by absolute alcohol, and then the rubber is freed from all traces of grease by means of ether. When the rubber solution has hardened, each bottle is further protected by coating the whole cap with paraffin, which has been previously raised to a temperature of $160^{\circ} \mathrm{C}$. A paraffin with a high melting point is selected if the vaccine is to be sent to a tropical climate. In dipping the bottles into the melted paraffin it is well to immerse the whole cap, so that the paraffin may fill up the interspace between the base of the cap and the neck of the bottle.

The bottles are now labelled, each label giving the number of the vaccine, its date, and that on which its sterility was tested, the nature and amount of the antiseptic added, and the dose for an adult in cubic centimetres and minims.

To withdraw the vaccine from one of the bottles for inocula tion it is only necessary to sterilise the cap in hot oil, or, better, in a hot antiseptic solution, and insert a sterile syringe - preferably graduated in tenths of a centimetre, and of a capacity of 5 c.cm. through the rubber cap. After the first puncture the needle is withdrawn and then reinserted and the syringe filled. The first perforation is made for the purpose of acting as an air valve to permit the entrance of air to replace the fluid withdrawn.

Should the entire contents of a bottle not be required at one time for the purpose of inoculating a series of persons, the cap may be again sterilised and the punctures sealed with rubber solution and paraffin as before.

With a view to providing for cases where isolated inoculations are undertaken, the vaccine is filled into glass capsules, each containing a single dose. These capsules are very simply made by drawing out pieces of glass tubing in the flame. The tips of these are broken of aseptically. They are then filled from a syringe with a measured dose of vaccine, and are sealed up again in the flame. The contents are readily drawn off, after breaking off the tip with antiseptic precautions, by inverting the capsule over the end of the needle of a sterilised hypodermic syringe.

Instructions describing the method of drawing off the vaccine, the method of performing the injections, and detailing the clinical symptoms which may be expected to ensue, are sent out with the vaccine.

\section{NOTES AND REFERENCE.}

1 Lancet, September soth, 1896. 2 The case in question was a somewhat anomalons one. It was the case of a man who, while in hospital for an injury to the foot. suddenly developed a high temperature and died within twenty four hours. The post-mortem examination revealed ulceration of the intestine, which was diagnosed as typhoid ulceration. ${ }^{3}$ In colfection incer, r lated by Major irth, R.A.M.C., on the troopship Dilwara, in October, r897. It appears from inquiries which were instituted by Major Firth, wha were supplemented inat no inoculated officers who came out in the same troopship have succumbed to that disease. We have invariably sound this ruber solution to be plask may be found to drain away at this joint by capillary attraction.

Major-General Leonard Wood, who, as will be remembered, began his medical military career in the United States army, has now been gazetted Major-General of Volunteers, and appointed Governor of Cuba.

\section{AN ADDRESS}

ON THE

INSANE AND THEIR TREATMENT.

Delivered before the Staffordshire Branch of the British Medical Association.

BY J. B. SPENCE, M.D.,

Medical Superintendent Staffordshire County Asylum, Burntwood, Lichfield: President Medico-Psychological Association of Great
Britain and Ireland; President of the Branch.

THe insane and their treatment have from the earliest times excited the sympathy and interest of all who felt for the afflicted and sorrowing of the human race, and many efforts are chronicled as having been made to alleviate the sufferings of tliose who in the distant past were supposed to be either possessed by evil spirits, or who were said by an old writer to be affected by

a disease of the soul resulting from a special habit of body, producing in some simple ignorance, and in others madness. of which latter there are two kinds, namely, that arising from human dis

the other from an inspired deviation from established custom. aberration of intellect in prehistoric days there is little doubt that two great factors with which we are confronted in this nineteenth century-drink and heredity-operated, though probably not in so marked a manner as among ourselves. Intoxication was not unknown to the ancient Egyptians, and without doubt exerted, in conjunction with other vices, its baneful influence in the development of various forms of mental disorder; and heredity, while perhaps not so widespread in its influence as with us, claimed its due share in the causation of brain troubles. Ancient Egyptian papyri describe the existence of a condition similar to our senile decay, while the treatment of madness, or sadness as it was sometimes called, by the employment of music appears to have been recognised centuries before the time

when the evil spirit from God was upon Saul, that David took a harp and played with his hand, so Saul was refreshed and was well, and the evil Epirit departed from him.

Indeed, as early as the days of Moses the Children of Israel, in the event of any departure from the due observance of the commandments and statutes which were laid down for their guidance, were admonished, that " the Lord shall smite thee with madness," to say nothing of the long category of other troubles which the 28th chapter of Deuteronomy appears to delight in holding over the heads of possible delinquents. Doubts have been expressed as to whether the madness which David was said to have feigned was not really an attack of epileptic mania, which Adam Clarke, the celebrated commentator, says was sent by God to save him from Achish, as one whose defection from his master and union with the Philistines was of no serious import. That the illness which separated the gr:at King Nebuchadnezzar from the company of his fellows for so long a period seems to have been one which not only affected his physical but also his mental state is generally admitted; and it is remarkable among other things for the fact that complete return to a healthy condition appears to have taken place after an illness of such a long duration, that nowadays one would give a more than doubtful prosnosis as to the probability of complete recovery were one consulted under circumstances of a like nature.

Among the Greeks Ulysses is said to have feigned insanity when compelled to join the army against Troy. Bellerophon gave a name to melancholia-morbus bellerophonteus. Ajax, afflicted by madness at the instigation of Minerva, sword in hand attacks oxen in the dead hour of the night, and exhausts his maniacal passion upon them in mistake for men; and Hercules, who is said to have suffered from epileptic insanity, appears to have indulged in conduct which would in more modern days, in his own interest and that of the general public, have insured his speedy transference to some such establishment as that which is so conspicuous an object in the landscape as one enters Stafford by railway from the south.

Hippocrates, writing five centuries before Christ, says: I see men become mad or demented from no manifest cause, and at the same time doing many things out of place............................ Who first referred these diseases to the gods appear to have been just such persons as the conjurors, purificators, mountebanks and charlatans now 
are. Such persons, using the Divinity as a pretext and screen for their own inability to afford any assistance, have given out that the disease is sacred, and have instituted a mode of treatment which is safe for themselves-namely, by applying purifications and incantations, and enforcing abstinence from baths and many articles of food which are unwholesome to men in disease.

Great was the man who at so early a period could write :

From nothing else but the brain come joy, despondency, and lamentation, and by the same organ we become mad and delirious.

Plutarch's knowledge of insanity would appear to have been of a very intimate nature, as his descriptions are lifelike in their word-painting. Caligula, the Roman emperor, who from his youth was subject to epilepsy, appears to have owed the condition of mind which resulted in the commission of such horrible erimes and excesses to the influence of that terrible disorder, which in his case is said to have been hereditary.

As to the treatment to which the ancients resorted little is really known. Nebuchadnezzar appears to have been so impossible that he was driven out and compelled to herd in the fields with the lower animals. Mechanical restraint was in all probability employed in controlling such furious homicidal impulses as have been attributed to Hercules. Plato directs that

if anyone is insane let him not be seen openly in the city, but let the relations of such persons watch over him at home in the best manner they know of, and if they be negligent in doing this let them pay a fine.

The practice of enchantments, the use of hellebore to purge the patient of his melancholy humour ; compulsory abstention from eating and drinking in order that the subsequent gratification of the senses should be all the more delightful to the patient; phlebotomy in company with a liberal diet; baths and the application of stripes, blows, and chains were some of the means employed to relieve the symptoms of one suffering from insanity. Celsus recommended that the patient should be startled suddenly so as to greatly terrify him, and a starvation diet with an emetic and smart purgative were remedies in his practice, while among the Romans the insane, or their friends for them, specially worshipped the Household Gods, sons it was believed of the Goddess of Madness.

Sufficient, however, has now been said to show that insanity was well known to the writers of antiquity and in all probability was of not infrequent occurreice, judging by the numerous and in many instances most accurate descriptions of mental disorder to be found scattered throughout the writings which have been handed down to us from those who lived and laboured long ago. Perhaps indeed more was known by the Greeks and Romans of the nature of insanity, and certainly more judgment appears to have been exercised in its treatment in remote periods than in the early days of Christianity and what is known as the Middle Ages.

A passing reference to the strange and varied forms of endemic insanity, such as the lyncanthropic madness of the Arcadians and the tarantism of the Scythians, brings us to a period concerning which there are numerous records of the existence of what has been denominated witchcraft, but which in many instances were undoubtedly extraordinary manifestations of insane disorders of a character with which we are happily not now familiar. That witcheraft was in the majority of cuses a form of melancholia with loss of personality, delusions of guilty conscience, morbid self-accusations and a desire to expiate their imaginary offence, is proved by the confessions of so-called witches and sorcerers at their trials-confessions which, even to their judges, seemed exaggerated and impossible. The descriptions which have been handed down to us of the midnight meetings, and the horrors of the orgies and revels carried out by those accused of witchcraft indicate a condition of things which can only have been produced in persons with diseased imaginations, as the grossest crimes and the most abominable acts of cruelty appear to have been practised. Young children were massacred, and their flesh, boiled with toads, serpents, etc., made into an ointment, which was supposed to possess certain mysterious qualities. In some cases an impious form of the Mass was celebrated at these orgies, and the most fearful blasphemies uttered over the consecrated wafer, which was used afterwards as an ingredient in their powders, ointments, and other medicaments ; the diabolical proceedings generally terminating with a banquet, at which it is stated that infant's flesh was a prominent dish. Witchcraft was for a time tolerated as an error which had been produced by religious fanaticism, but later on the French punished by fire those who attended the witches' revels, and when in the eighth and ninth centuries the Devil was supposed to take an active share in these unholy festivities, the Church commenced to take serious notice of the practices carried on, and the institution of the Inquisition in $1183 \mathrm{had}$ the effect of not only bringing to trial those who were rightly accused of witchcraft, but many sane persons were made victims of the Inquisitors, who, to satisfy their private revenge, or to please those who were in power, condemned not only the guilty but the innocent to the stake.

For many years epidemics of demoniacal and impulsive forms of insanity appear to have broken out throughout England, and in order to check these, witch trials and executions became so common that thousands of persons are said to have suffered the death penalty in consequence; but the spread of civilisation and of the reformed religion had more to do with the improvement of affairs, which dates from the end of the seventeenth century, than the rigorous enactments of the Church, which failed lamentably to distinguish between crime and madness. To the members of religious brotherhoods, however, should be given the credit of whatever slight redeeming features there may be found in the treatment of the unfortunate beings who in the Middle Ages suffered from insanity; and as the monks could never quite free themselves from the belief that those who were mentally afflicted were in reality possessed with devils and evil spirits, the treatment which their religious fervour and gentle compassion suggested was of a more kindly nature than the stones, sticks, and death by fire which was the common mode of treatment at that period, so that in course of time churches, monasteries, and holy wells furnished a refuge for the insane, who were there protected in some degree from the results of the popular abhorrence and dread of men and women who were held to be of a different species to the rest of mankind-" a set of animals, or positive incarnation of devils who had taken on human guise."

The remedies prescribed in the treatment of the insane in those early days were both numerous and curious. The mugwort which is still employed in country places as a cure for falling sickness was largely used in the early Saxon times, while henbane formed one of the many ingredients of what was somewhat inelegantly called a "spew drink" much in vogue in cases where a demon was supposed to possess a "fiend-sick" man. The combination of priest and physician, which held good for centuries in the treatment of "diseases, is manifested in the directions given for the proper administration of remedies which were to be drunken out of a church bell, while seven masses were to be sung over the herbs of which the concoction was composed, and to the lunatic himself was assigned the singing of psalms, while the priest completed the mystic circle by the intonation of certain supplications which added to the value of the medicaments to much the same extent as the placing of a cipher before a sum expressed in decimals. For epilepsy in a child the brain of a mountain goat was to be drawn through a golden ring, and then given to the child to swallow before it tasted milk. Wolves' flesh, if well cooked, was effectual in hallucinations, while for mental vacancy, bishops wort, lupins, betony, fennel, cat mint, and agrimony, when well mixed with ale, were highly extolled.

In temptations of the fiend and for nocturnal visitations

Seek in the maw of young swallows for some little stones, and mind that they touch neither earth nor water or other stones; look out three of them, put them on the man on whom thou wilt-him who hath the needand he will soon be well; or, better still, use a salve composed of ewe-hop wormwood, bishops wort, and lupin: put these worts into a vessel, se them under the altar, sing over them nine masses, boil them in butter an sheep's grease, add much holy salt, strain through a cloth, and throw the worts into running water.

The salve thus produced was to be smeared on the forehead of the afflicted person, and also on his eyes and wherever his body was sore ; he was further to be censed with incense, and signed frequently with the sign of the Cross; the result can scarcely be considered doubtful; " his condition," says the old writer, "will soon be better."

The influence of the moon in the production of insanity was recognised in those far-off days, for, says Giraldus of Wales "those are called lunatics whose attacks are exacerbated every month when the moon is full," and it is the same writer who refers to the holy well. of St. Winifred in Flintshire, which retains to the present day, in the opinion of some, 
many of the miraculous powers which were ascribed to it in the twelfth century, although unlike many other wells of whieh I have yet to speak, among them is not mentioned the cure of those afflicted with mental disease.

One of the remedies employed in Cornwall was called "bowssening" or ducking, and is so curious that a short account of it $^{1}$ may prove interesting. The custom was observed in many places. At Altarnun, about eight miles from Launceston, was a church near which was situated a pool, from which water was allowed to fall into an enclosed space. On the surrounding wall of this space the patient was made to stand with his back to the water, and was then, by a sudden and unexpected blow, thrown backwards into it, after which

A strong fellow took him and tossed him up and down alongst and athwart the water until the patient, by foregoing his strength, had some what forgot his fury. Then was he conveyed to the church and certain St. Nunne had the thanks, which handing, if his right wits returned, bowssened again and again while there remained in him any hope of life
or recovery.

Scotland is celebrated for, among other things, the number and potency of its lunacy healing wells, and the extraordinary superstitions which attach thereto. St. Fillan's well, in Perthshire, has long been extolled as possessing sovereign virtue in the cure of madness; and as late as the year 1793 a writer observes that about 200 people afflicted by a disorder of the mind are annually brought to try the benefit of its salutary influence; the patients being conducted by their friends thrice round a neighbouring cairn, on which is deposited a small offering such as a bunch of heather, or may be a bundle of clothes, then after being thrice merged in the sacred pool the sick man is bound hand and foot, and left for the night in the chapel which stands near. If the maniac is found loose in the morning good hopes are entertained of his recovery, if still bound his cure remains doubtful, while-and this is not the most astonishing portion of the narrative-it sometimes happens that death relieves him during his confinement from the troubles of life. St. Ronan's well, the well of Inch Maree, and one in Stirlingshire are also noted as having been credited with the possession of remarkable healing virtues; while in Ireland, in the valley of the lunatics near Tralee are two wells the waters of which, when taken internally at the same time that the cresses which grow on the margin are eaten, are believed to effectually restore a madman to mental health. To effect a similar purpose lunatics were frequently bound to holy crosses, and to the pillars of churches. Says an old writer, those "labouring under various disorders, especially the furious and those vexed with demons, are bound in the evening, and in the morning are often found sane and whole, and are restored to their liberty." Burton, in his Anatomy of Melancholy, published in 162I, gives a graphic, though painful, account of the appearance and treatment of the lunatic in his day, and attributes the disordered condition of the mind "to the presence of certain peccant humours in the body affecting the brain which required elimination," and so the physician of that day, influenced by his belief in the connection hetween the liver and insanity, recommended the use of emetics, purges, opening the veins under the tongue blisters, issues, shaving of the head, and (most efficient of all) the anointing of the backbone with a choice balsam composed of earthworms or bats.

It will be seen that the treatment of the insane in the seventeenth century was certainly no whit better than that described by the writers of antiquity, such as Hippocrates, Plutarch, and Colius Amelius. Indeed, the state of mind of the unhappy wretches who were stoned, half drowned; wholly burned, and generally neglected and ill-treated, was completely misunderstood, and where anything approaching considerate treatment was employed it was due, either to the religious fervour of the monks or to the opinion that had deocended from generation to generation, from very remote periods, that in persons suffering from insanity there was an excess of bile in the blood, and that emetics and purges of no gentle description were necessary for its due elimination.

That something more, however, was done for the insane even in the early days now under consideration is eviden from the fact that at the commencement of the fifternth century lunatics were confined in Bethlm Hospital, which had been founded a century and a half previously on the site now occupied by the huge Liverpool Street terminus of the Great Eastern Railway Company, and in 1598 there existed a religious house "wherein sometime were distraught and lunatik people," near to the junction of Charing Cross and St. Martin's Lane, the probable position of the building being near the spot where now stands the Havelock Statue in Trafalgar Square.

The treatment of the poor creatures confined in these establishments was of a rigorous description, and this is evident from accounts we have left us by eye-witnesses of the scenes which took place. Evelyn says that he "stepped into Bedlam, where he saw several poor miserable creatures in chains." Another writer states that "the men and women in the old Bethlem were huddled together in the same ward," while the account books of the asylum record the expenditure of various sums in the purchase of fetters and straw. As lately as the year 18 15 evidence was given before a Committee of the House of Commons that a person was restrained in the following effectual manner :

A collar encircling the neck was fastened by a chain to a pole fixed at the head of the patient's bed; an iron frame, the lower part of which encircled the body, the upper part being passed over the shoulder, having on either side apertures for the arms which encircled them above the elbow, and a chain passing from the ankles of the patient and fastened to he foot of the bed.

Horrible as all this is, one cannot feel surprised when it is known that to control a body of ' patients which sometimes exceeded the average number of 122 there were only employed three male and two female attendants, or ketpers as they were called, and that it was the duty of the male attendants to assist the female when the women patients, owing to their refractory conduct, required additional strength in order to coerce or control them.

That no particular attempt at concealing the condition of affairs existed is evident from the fact that for years Bethlem and its inmates were one of the sights of the metropolis, and visitors were admitted upon payment of a small sum of money. This custom however was discontinued in 1770 not long before the second Bethlem in Moorfields was condemned, and the building which is known to many of us in St. George's Fields was decided upon, but even in this, the third and best of the Bethlems, at its commencement the windows of the patients' rooms were not glazed, nor were the rooms warmed in any way; there was no provision for lighting the rooms at night, and the window openings were placed high up in the walls so that patients could not possibly see out. Bethlem was not the only institution in which such regrettable practices as I have very briefly detailed were in vogue. St. Luke's Hospital in London and an asylum in York-not the Retreat-were subsequently shown to have quite as bad a record, and indeed the condition of affairs in the private asylums which were numerous and abominable and in the workhouses of the kingdom, was so very dreadful that at the present time one marvels at the opposition which arose against any alteration in or addition to the law which would enable other and better and properly supervised accommodation to be provided for the helpless creatures who suffered indignities which nowadays it makes one shudder even to think of.

The lunacy of King George III and the mental incapacity of Lord Chatham had directed the attention of the public to the way the insane were treated, but it was not until the days of Pinel in France and of Tuke in England, followed as they were by the practical and philanthropic efforts of Lord Ashley, better known to a later generation as Lord Shaftesbury, that any attempt was really made to alter the sad condition of affairs which had existed for so long a period. Germany had also been aroused to the necessity for according to the mentally afflicted greater protection than they had up to this period enjoyed, and we find that as early as 1773 certificates of admission from medical men were required in Berlin, that in 1785 a fairly managed hospital for the insane existed at Frankfort, and a few years later at Lubeck and Brunswick but as far as this country is concerned no doubt the influence of Pinel and Tuke predominated in producing the results which have since followed their introduction of a more enlightened and generous mode of treatment. In 1783 the Revolutionists were all-powerful in France, the Salpêtrière and Bicetre were huge prisons for the insane in Paris, and Pinel. a physician to the latter establishment, was one of those apostles of science, who, filled with energy 
and courage to defend his beliefs, determined that an effort should be made to afford the insane not only freedom from the barbarous treatment to which they had been subject, but also that they should be looked upon as human beings afflicted with a disease of the brain, and requiring medical care and treatment in hospitals just in the same way as other human beings afflicted with maladies in various parts of the body. In this Pinel forecast the modern hospital for the insane, of which I shall have something to say later on.

When Pinel applied to Couthon, one of the leaders of the Revolution, for authority to take the irons off the insane-

He ran the risk of attracting the distrust and suspicions of men always disposed to find everywhere plots against themselves, Couthon replied: "Citizen, I shall go to-morrow to the Bicêtre to inspect it, but woe to thee if thou hidest the enemies of the people among the lunatics."

to he did on, the following morning to examine the insane; but he soon tired of the pandemonium of screams and yells, and the clanking to Pinel he said: "Look here, citizen, art thou insane thyself that thou wilt unchain such animals?"

"Citizen," replied the courageous and practical philanthropist, "I am convinced that of treatment." "Well," said Couthon, "do with them what thou likest, but I fear thou wilt be the victim of thy presumption."

Without delay Pinel commenced the stupendous task, for which he had previously made adequate and necessary arrangements, and in less than a week he had freed more than fifty lunatics from their manacles. "Some," says the narrator of the tale, "were exceedingly dangerous, and among them were patients who had been in chains for ten, twenty, and even thirty years."

Pinel followed up his great work at Bicêtre by similar efforts at the Salpêtrière; but, like pioneers in every age, he met with opposition on all hands-not only from the ignorance of the public, but also from the self-interested resistance to his efforts of those in official positions. Indeed, although much was accomplished, much remained to be done, as Esquirol -another great name on the list of enlightened and humane physicians-writing in 1819 , laments that

these unfortunate people are treated worse than criminals, and are

Simultaneously with the great work which was being carried on in France, William Tuke, a member of the Society of Friends, had commenced a similar crusade in this country, stimulated by a knowledge of the state of affairs which prevailed in a certain asylum in York to which I have before referred. Tuke, who had also, at a visit which he paid to St. Luke's Hospital, ${ }^{2}$ seen the inmates bound in chains and lying in straw, was filled with sympathy, and, more than that, fired with zeal to improve such a miserable state of affairs. He consulted with other members of the religious body with which he was associated, the result being that, having overcome many difficulties which were suggested and others which arose in practice, he had the satisfaction ultimately of seeing a house known as the Retreat erected in the neighbourhood of York, and system of treatment adopted which was the direct antithesis of what had gone before. The Retreat was a place

in which the unhappy might obtain a refuge-a quiet haven in which the shattered bark might find the means of reparation or of safety.

Tuke had at times his moments of despair. "All men seem to desert me in matters essential," he writes ; while his biographer wonders

that the proposal should have met in the first instance with considerable opposition, and that the institution had to struggle through man difficulties into existence.

But if the sane and healthy ignored and opposed this great and good work, the unfortunate beings for whom Tuke was labouring appreciated fully the changed condition of affairs. A patient was admitted to the Retreat who had nearly lost the use of his limbs from being chained, and for some time it was necessary to lead him about like an infant. He was found to require no restraint. and was afte a while able to walk without assistance. When one of his friesds visited him. and asked him what he called the place, he replied with intense

A book written by Mr. Samuel Tuke, entitled a Description of the Retreat, by the great interest which it evoked in the experiment being carried on at York, proved the means of arousing the attention of the public, first to the abuses of the old asylum at York, and then to others of a like nature in different parts of the country, especially in and about the metropolis, the result being that, while the defenders of the old system fought vigorously on behalf of their views, a strong public opinion was developed, which pressed for and ulti- mately obtained the appointment of a Select Committee of the House of Commons, before whom many witnesses were examined and much evidence taken; and finally, owing to the report presented by this Committee, legislation was called for, which by successive enactments has produced the marvellous change which has been since effected throughout this kingdom, and by its influenee and example throughout the civilised, world in all that ministers to the comfort and care of the mentally afflicted.

Several Bills, having for their object the better regulation of madhouses, were introduced in the early part of this century, some of which, though successful in one House, were rejected in the other; others were withdrawn, owing to the opposition with which they were met; but, to shorten this portion of my subject, let me briefly say that in the years 1747, 1763, and 1773 various Bills were introduced, which were of no practical value, and were consequently rejected. The illness of King George III, which commenced with a slight attack of insanity in 1765, and his public thanksgiving for recovery on April 23rd, 1789, no doubt kept the subject well before the public: but not even the recurring attacks from which the King suffered in 1801 and 1804 , nor his final attack in 1810, were sufficient to induce Parliament to pass a compulsory measure, although in 1808 an Act known as Wynn's Act was passed, rendering it lawful for justices in every county in England and Wales to take into consideration the propriety of providing a lunatic asylum for the reception of patients within the county. This enactment, not being compulsory, failed to accomplish the object of its promoters, as only nine out of fif $y \cdot t w o$ counties took advantage of the powers conferred upon them; but among these it is of local interest to notice was the county of Stafford, which in 1818 opened an asylum in this town (Stafford) for 120 patients at a cost of $£ 36,500$-a very different establishment, no doubt. from that which is now administered with so much sympathy and consideration for those under his care by my colleague and much esteemed friend, Dr. Christie. Lord Shaftesbury's Act of 1845 and the amending Act of 1853 , introduced by Lord St. Leonards, constitute what have been well called the Magna Charta of the liberties of the insane, as these laws enacted the establishment of a permanent Commission of Inspection, the compulsory erection of suitable buildings throughout the kingdom, and specified in detail the method of certification which with certain slight modifications was applicable to private and pauper patient alike. In the year 1845 , when the office of Commissioner in Lunacy was first instituted, there were 20893 persons ascertained officially to be insane in England and Wales, and for the duty of visiting and inspecting this large number of lunatics three medical men and three barristers were ordered to be appointed. On the Ist day of January in this current year there were 81,258 lunatics under treatment in asylums alone in England and Wales, and it appears somewhat anomalous that with this enormous increase of certified lunatics requiring inspection the visiting staff of the Commission should remain of exactly the same strength as in 1845 .

The practical result of all this legislation was that the searchlight of inspection was turned upnn the dark places which had exiated for so long, and the influence of such men as Conolly of Hanwell, Gardiner Hill of Lincoln, Gaskell of the Lancaster Asylum, and others became a factor which, combined with the energy displayed by the new Commissioners and the interest taken by a large section of the public, soon brought about changes which converted the madhouses of the past into the hospitals for the mentally afflicted of the present day.

In that wonderful old book. William Cullen's First Lines of the Practice of Physic, published in 1784 , the chapters on mania or madness afford a very clear idea of the strange method of dealing with the insane even of so advanced and clear-sighted an exponent of our art as the celebrated Professor of Physic in the University of Edinburgh, and First Physician to His Majesty of Scotland :

Angry passions are always rendered more violent by the indulgence of the impetuous motions they produce, and even in madmen the feeling other otherwise occasion. It is never desirable to con re the patient to a within doors and it should be in a place which presents as few objects of sight and hearing as possible. 
He also directs that, "fear being a passion that diminishes excitement," the patients should be inspired " with the awe and dread of some particular persons, especially of those who are to be constantly near them; this awe and dread is therefore by one means or other to be acquired; in the first place, by those in charge of them being the authors of all the restraints that may be occasionally proper, but sometimes it mav be neressary to acquire it even by stripes and blows; the former," he is careful to observe. "altbough having the appearance of more severity, are much safer than strokes or blows about the head. cullen also recommends the use of the surprise bath, which, he says, consists in throwing the length of time, and pouring water frequently upon the head, while the whole of the body except the head is immersed in water, and thus managing the whole process, so as that, with the assistance of some fear, a refrigerant effect may be produced.

The employment of restraint in the treatment of the insane might well by itself form the subject of a paper; suffice it to say that in this one particular vast advances have been made, the use of muzzles, leather gloves, straps, handcuffs, etraitwaistcoats, and the many other modes of applying restraint to an unruly patient are now unknown except in very special cases, and then usually practised for surgical reasons only; seclusion - a very valuable and necessary method of treatment in some extreme cases-is reduced to a minimum, while anything in the shape of narsh usage towards a patient is so rare that its occurrence gives rise to the same amount of painful surprise and public animadversion as is occasioned when the superin. tendent of a Sunday school is found guilty of some abominable offence towards one of his scholars quite incompatible with the blameless life he was supposed to be leading.

The general surroundings of the lunatic have also been changed for the better, the wards of a modern asylum-such as the County Council of Stafford, with far-sighted and enlightened liberality, has provided at Cheddleton, in the north of this county-are provided with every comfort and convenience, a good library, daily papers, amusements of various kinds, occupation suitable to the requirements of each patient, and a liberal dietary are some of the changes which have been brought about. The persons employed in the direct charge of the patients are of a much superior type to the keepers-hateful word-of the beginning of the century and the amount of freedom which is now enjoyed by the inmatps in all well-managed asylums renders these institutions most desirable places for a short period of retirement from a world which does not appreciate the morbid miseries of the melancholic or the noisy and violent conduct of the acutely maniacal. Even in the workhouses, especially those belonging to the large unions-such as Dudley, Walsall, Stoke, and many others-the accommodation provided for the epileptic and imbecile inmates has been much improved of late years, and a manifest desire to still further brighten the existence of these chronic unfortunates is evinced by those whose duty it is to look after their interests.

About five years ago the Medico-Psychological Association of Great Britain and Ireland introduced a system of training the nurses and attendants of asylums with a view of improving their position by giving them the same opportunities of acquiring a knowledge of nursing as their hospital analogues have had for some years. A secondary but none the less important effect of this innovation must be that the fact of having trained attendants will prove of incalculable advantage and benefit to the inmates themselves, as it substitutes the hospital for the prison feeling, provides prompt and competent attention in case of emergency, and the unmixed blessing of skilled nursing when acute illness has to be encountered. To the members of the medical staff of an asylum the knowledge that their instructions will be fully and carefully carried out, and that the patients are in the hands of properly educated men and women is a source of the greatest comfort; and to you, gentlemen, who have at times to under. take the treatment of mental disorder in private houses, the knowledge that you can procure the services of a trained mental nurse to assist you in your trying work must be of the greatest importance.

It is not my purpose this afternoon to give to you an account of the advances which have been made in the investigation of insanity from the scientific side of the question, but let it not be supposed that while development has taken place in the attention paid to the material welfare of the insane, the building of mental hospitals, increased medical care, and more civilised methods of treatment, nothing has been done to encourage and cultivate the special scientific study of insanity.
In the majority of the larger asylums a pathological department exists, where good and useful work has been done in the past ; but a still more important step has within the last few years been taken, at first in Edinburgh, and soon after in connection with the London County Council asylums. by establishing a laboratory presided over by a pathologist of eminence, whose sole work consists in the investigation of the cause and course of the disease in the cases which are studied clinically in the asylum wards during life, and in which, after death, opportunity is afforded for a careful and complete attempt to unravel some of the specific problems with which insanity abounds.

During the past few months a movement has been set on foot with a view to direct the attention of the committees of the asylums of the Midland counties to the importance of establishing a similar laboratory in Birmingham or some other convenient centre, so that valuable material, which at present is practically wasted, may be utilised in such a way as not only to promote the cause of scientific research, but to bentfit both patients and ratepayers by opening up new and successful methods of treatment, and by investigating causes, the prevention of which would tend to diminish the number of those attacked by mental disorder, and thus reduce the outlay. which is rapidly becoming a much too prominent feature in the accounts of the county and of the National Exchequer.

In conclusion, let me say a few words as to the duty which medical men who practise their profession outside asylums owe to the insane. Even in the scientific aspect of the question of which I have just been speaking, the study of the symptoms which point to an attack, the early identification of functional and the more curable phases of mental disease, the education of the public in those preventive measures which may have a tendency to minimise the extension of insanity, and above all, the study of the sane person from a psychiatric point of view, are all of them more in the province of the hospital physician and the general practitioner than of their specialist brother who sees little else but well-marked manifestations of damaged brains, and in only too many instances has but little chance given him of doing permanent good, as progressive degeneration with destructive changes in the neuron have usually stamped the case as hopeless before he has had an opportunity of examining into the condition of the patient.

Now and then cases come before the general practitioner in which an early recognition of symptoms might lead to such treatment as would probably prevent a more serious development into insanity ; and, above all, those cases of drink madness which are sent to asylums in such considerable numbers might in many instances be just as well looked after either in their own homes or in the wards of the workhouse as in an institution, a residence in which for however brief a period, or for however transient an attack, has unfortunately in the eyes of the public the effect of stamping a man or woman as one who from that time forth should be looked upon with suspicion, and deprived of many of the privileges which he or she would otherwise enjoy.

The influence which members of our profession can bring to bear upon those who have the making of our laws, and upon others who owing to their social position are able to assist in the initiation of reforms, might well be exercised to facilitate the passing of a short Bill entitled "An Act to Amend the Lunacy Acts," which was introduced by the Lord Chancellor in the last session of Parliament, but which, owing to the pressure of other business, had to be sacrificed to important, though not less urgent, measures. Especially would I direct your attention to the necessity for supporting one of the clauses in the Bill referred to, which was designed to legalise the placing of single patients under the care of medical practitioners without the certification which in many instances proves a barrier to arranging for the private care of cases of incipient or slight forms of insanity, Relatives and friends often shrink from the publicity of the present method of certification, and prefer to leave the patient without that care which is so essential in order to promote recovery rather than call in the aid of the judicial authority whose intervention is now a necessary part of the proceedings. A deputation consisting of members of the Parliamentary Committee of the British Medical and of the Medico-Psychological Associations waited upon the Lord Chancellor with a view to 
press upon his notice the advantage which would arise from a modification of the present system. The interview was a very satisfactory one, as the Chancellor, after full consideration of the various points which were placed before him, agreed to the wishes of the deputation, the result being that a clause was drafted and inserted in the Bill which, while removing the objection alluded to, would give the patient and the public an ample guarantee that no man or woman would be placed under care without having the advantage of proper supervision by the Commissioners in Lunacy, who, as matters now stand, have no authority over, nor indeed cognisance of, the many cases who, either in their own homes or in unlicensed premises, are secluded in such a way as to lead some to think that we are reverting to methods of dealing with the mentally afflicted, which, to put it mildly, are not consonant with modern ideas.

The suggestion that has been made; if duly legalised, would enable a patient suffering from a mild attack of insanity, or, as the clause puts it, "suffering from mental disease, but that the disease is not confirmed," to be placed in private care for a period of six months, provided that a medical practitioner certifies to the necessity for such treatment, and that the certifying practitioner and the person who undertakes the management of the case should notify the fact to the Commissioners in Lunacy, who would have the power of visiting and observing whether all that their experience has taught them to be necessary in such cases is done in the interests of the patient. In this way many who would otherwise be neglected, or if certified would be classed as " a lunatic or person of unsound mind," might be given a chance of recovery before the termination of the six months, while at the worst, if improvement had not taken plaee, the transfer to an asylum would in all probability be then recognised by the friends as a painful though unavoidable necessity.

The establishment of a clinic at asylums adjacent to large towns has had excellent results in the treatment of the incipient forms and early stage of insanity, and a like department in every large general hospital would doubtless after a time be recognised as of inestimable value in many cases which at present drift on to that point when nothing is left to the medical man when consulted but to advise the asplum and nothing but the asylum.

I have now to thank you for your presence here, and to say that my colleagues and myself are at all times most desirous of giving our medical brethren an opportunity of seeing all that goes on within the wards of our asylums and of replying to any questions respecting patients in whom you may be interested. We want to do away with the bad old system of not only locking our patients in but of locking the public out, as we believe that the more the outside world knows of the work done in asylums the less we shall hear of the suspicions and complaints which are happily becoming fewer and fewer every year, and the sooner will the time come when the aversion towards bringing a patient to a hospital or home for the insane will have passed away for ever, even from the minds of those who at present harbour memories of the time, now long gone by, when it might be said of those who had the misfortune to require treatment in such an institution, "Abandon hope all ye who enter here."

Enough, I trust, has been said to show that the subject of the insane and their treatment occupies at the present day a very different position in the mind of the public to that which it held at the beginning of the century, and that the large sums of money which have of late been spent in the provision of asylums, and in otherwise caring for the insane, have not been wasted nor, indeed, expended before they were required; but, in this, as in everything else, progress is the watchword of the day, and, while those who are in close touch with this special branch of our professional work, whether laymen or doctors, feel that much has been effected, yet they freely admit that much still remains to be done. We therefore ask for your sympathy in what is at times a trying and difficult position, for your co-operation in elucidating some of the problems in which we are interested, and for your active support in pressing forward any measures of reform which may from time to time be considered advantageous on behalf of those who are often looked upon as being of little account in this world, mere cumberers of the ground, and past all human help.

\section{Notrs.}

1 Abbreviated from a History of the Insane in the British Isles, by the late Dr. Hack Tuke, to whose valuable works I am indebted for much information upon the subjects treated of in this address. 2 The late Dr. Arlidge, who was for many years a member of the Staffordshire Branch of the British Medical Association, and whose death was mentioned with expressions of the deepest regret at the meeting before which this address was delivered, was at one time associated with St. Luke's Hospital. According to a biographical notice in the BRITISH MEDICAL JoURNAL of November 4th, 1899 , Dr. Arlidge, in his early days, "gave much attention to the subject of lunacy, and attended at Hanwell Asylum the lectures of Drs. Conolly and Hitchman, whose friendship he enjoyed throughout their lives....... He became Resident-Superintendent of St. mechanical restraint........In 1859 he wrote a work on the State of Lunacy and the Legal Provision for the Insane, which was dedicated to the Earl of Shaftesbury, Chairman of the Commission in Lunacy, and in 1857 he wrote for the Prychological Journal a series of reports on the Lunatic Asylums of France, Italy, and Germany."

\section{THE BROMIDE SLEEP : A NEW DEPARTURE IN THE TREATMENT OF ACUTE MANIA. BY NEIL MACLEOD, M.D., Shanghai.}

To have to consign a case of acute mania to a padded room in a gaol, and to have to treat it there without skilled attendants, there being no proper provision for such a case within some thousands of miles of Shanghai, naturally reconciles one to adopt an alternative which may appear, or actually be, heroic, but which promises to deal with the case successfully in the patient's own house.

I have not met with anyone who has seen the condition which I have termed "the bromide sleep" apart from those cases in which I have induced it, nor can I find any reference to such a state intentionally produced as a therapeutic measure. An approach to it has been made in the treatment of epilepsy, but neither have such doses of bromide been given, nor such a condition produced as I have described in recent papers ${ }^{1}$ on the treatment of various drug habits, etc. By " the bromide sleep" I mean a condition lasting from five to nine days, in which the subject sleeps day and night, and from which he cannot be roused. He cannot walk, stand, sit, speak, or carry on any of the higher cerebral functions. If left to himself he will not feed or drink; indeed, he cannot even ask for food or drink, being unconscious of these needs, but can be sufficiently nourished with milk during that time. He will pass urine and stools in bed if left to himself, but can be prevented from doing either by timely suggestion of these needs on being placed on a commode and held there for a few minutes every six hours. The loudest sound, the strongest light will not disturb him. During this period the higher nerve centres are rested to an extent so complete as cannot be attained in any other way, so far as I am aware. Following this sleep is a gradual recovery of the powers of locomotion, speech, thought, etc., the progress being daily visible, lasting about a fortnight-in all about twenty-one to twenty-four days. This fortnight is also a period of comparative rest, there being a gradual awakening of mental power and a passage from a disordered to an ordered state as regards that function. This bromide sleep I have produced nine times, and, so far as I can judge, safely and with advantage in the treatment of the various maladies for which I have used it, with one exception. This was a case of morphine and cocaine habit, in which a double pneumonia supervened and led to a fatal result. ${ }^{2}$ This case was the first of an epidemic of pneumonia, numbering more cases and deaths in a few months than had occurred in the previous twenty-one years of my residence in Shanghai. Apart from this case, and even here before the intercurrent pneumonia, I have not seen any interference with respiratory or circulatory function sufficient to give rise to anxiety. With perseverance, care, and a tumberful of milk every two hours to seven tumblers, little loss of weight need occur except from wasting of muscles. After recovery in no instance has any indication of interference with nervous function been observed.

Manifestly, more cases will have to be observed before it is possible to estimate the full advantage and danger, if any, of this sleep, and as, in the natural course of things, I shall have but few opportunities here of seeing many such cases, I 